\title{
The Affective Database: Symulation and Enacting Worldhood in the Film-worlds of Scott Barley
}

\author{
JACK BUCHANAN, Independent Researcher
}

\begin{abstract}
This article offers an alternate evolution of Lev Manovich's (1999) concept of the database film, explored through the work of Welsh experimental filmmaker Scott Barley. Suggesting the existence of an affective type of database, this codifies their production as a form of ecological activism which phenomenologically affects viewers and creates a worldhood that each film inhabits. Viewers emerge as agential participants, which this article argues is an entanglement that occurs and continues long after the film's initial release. Barley's works often eschew formulations of humans, and instead invoke abstracted images of the world and wild animals, engendering an altered process of thought that attempts to avoid, reject and/or refute anthropocentrism. As Barley's work continues to catalyse considerations of darkness, time, space and Jean Baudrillard's simulation (1994), I argue that such films allow moments of stasis and stillness that are akin to death, bringing forth further considerations in viewerparticipants about the world(s) they inhabit.
\end{abstract}

\section{KEYWORDS}

Database Films, Simulation, Struction, Scott Barley, Ecocinema

\section{Introduction}

When we use language to describe, or explain an image, we are in a sense, objectifying it, and in turn, we are killing it. We kill its mysteries and silent beauty through our inane objectification. (Barley, Notes On Cinema)

Scott Barley is a Welsh experimental filmmaker whose work ranges from hyperkinetic twominute short films, to six-hour marathons of unmoving still images. Although this article is written from, about, and perhaps for his work, the words quoted above ring particularly true here. Thus, where possible, I am not attempting to describe or explain Barley's images. His films are available, free, to anyone with internet access, and thus it does not feel exclusionary to leave this attempt out. Instead, I will think through what his images can do, different and distinct from assigning some description of what they have done, do, or will do. Barley's words, however, can be thought through and explained in conventional language. They form an inextricable, though not limitless, link to his visual work, providing not just contextual clues, but full philosophical elaborations on his filmmaking process and purpose. Though they are separate from his films, they exist with his visual work in this study. 


\section{Three Births}

For Lev Manovich, the first birth of database cinema extends back to Dziga Vertov's Man with a Movie Camera (1929), though we can also think of its first birth as the moment Manovich published Database as a Symbolic Form, in which he described the rise of 'many new media objects [that] do not [...] have any development, thematically, formally or otherwise, which would organise their elements into a sequence' $(1999,80)$. Non-linearity, and the existence of 'interface(s)' - different modes of involvement with a collection of media material - defined the database film. Since then, the definition has been revised several times, giving rise to accounts that obsess over structural features of the database, and taxonomical accounts that try in vain to categorise the types that exist. In many of these, data is framed as requiring organisation to create meaning, and therefore information. They theorise the communication of information as the ultimate goal of the database (Vesna 2007). This recalls Manovich, who sets narrative and database structures as opposing creative endeavours. Marsha Kinder refutes this, writing that these two endeavours are compatible and indeed 'crucial to the creative expansion of new media, since all narratives are constructed by selecting items from a database' $(2003,348)$. However, this does nothing to dispel the myth that the sole function of the database is to store, order and divide information. After all, narratives are communicated through information via what most scholars describe as the language of film.

That is not to say that these theories of database films are to be ignored or cannot be viewed positively. As a way of theorising the quickly changing landscape of digital media, the database film has been the catalyst of much more than just the digi-capitalist dogma of meaning means information which informs value. The growth of ecological and social concerns explored through this meta-genre has highlighted key problems with how the database is constructed, and how it is viewed. In its original form database cinema is the re-purposing, re-using and reconfiguring of existing material to create new works, without the consumption of film stock or the purchase of expensive digital equipment emblematic of the 'monopoly relation to the earth that digital industries' corporate capitalism is trying to maintain' (Parikka 2015, 80). Despite the limits around which Manovich structured his definition, he did recognise that the database could create multiple interfaces to a singular collection of material. Not only this, but that there could be 'multiple trajectories through a database' (Manovich 1999, 87), where the interface and database remain the same, but the audience (or, indeed, algorithm) engage with them in different ways. The second birth of database cinema can thus be thought of as eco-cinematic: these are films that engage with environmental concerns, present alternatives to anthropocentrism, and transcend some of the ecological problems of filmmaking (MacDonald 2004; Willoquet-Maricondi 2010).

The smartphone and its relatively democratising quality in the production of media has been central to this - especially in the creation of database cinema. It is with the smartphone that Barley creates the majority of his work. Of course, Barley's films are not the only ones to be made on a smartphone, but his filmmaking process - which we have seen is important when considering database cinema - is unique to him. Barley shoots on his phone for months or years, creating a database of work for himself from which he later begins to form films. His films are 
composed of layers of different footage - an upcoming work-in-progress features over eleven thousand shots displayed at once - and his films are keenly concerned with ecology, philosophy, and how we engage in the act of viewing films. Barley (Notes On Cinema) writes:

I wonder whether we will eventually live utterly inside ourselves. It is not hard to imagine, as we sit, immersed in the cyberspace of our smartphones. Perhaps we will ultimately become the body without organs. The body without organs that Artaud and Deleuze proposed. Our body will be emptied, rendered void, it will be nothing but a husk $\ldots$ and then cinema will take its place.

This extract lays bare his preoccupation with the act of viewing and the relationship of the body to cinema.

It is here that I propose a third birth of the database, one that does not require the communication of information to be the defining purpose of its existence, nor that is limited by the ecological factors of its production. Instead, let us allow the creation of an affective database, which relies on the unthought, the non-thought, and the beyond thought of perception to be its method of communication. Not a database of information, but of feeling; of an 'immanent significance' (Merleau-Ponty 2002, 26) that allows meaning to be something other than a dry, information-sharing artifact that only holds value as such. This third birth, the rebirth, has already happened through the work of Barley, whose films avoid logic and contain the immanent significance that lends itself to affective encounters with a database film, not the 'using' of one. His work inherently rails against the idea of a structured database in lieu of the affective, the felt. Barley's database is one of darkness, simultaneity, the creation of filmworlds that manifest a slowing of the rhythm of semiocapitalism (which we will return to later) and present and engage us in non-human, post-anthropocentric worlds. Complementing its recycled nature, this essay will re-use and re-configure existing work on the database in the context of affectivity and film-worlds, to theorise this new database cinema through the examples present in Barley's output.

\section{Struction and Entanglement}

Manovich (1999) writes that the only way to create a pure database is to spatialise it. I do not want to give credence to the idea of purity as a pinnacle, since the very idea of a database that is pure exists only abstractly as an essence, but the idea is worth exploring nonetheless. Certainly, Barley engages in the spatialisation of his databases. In a self-conscious tension, he layers images of shot footage, photographs, and hand drawn pictures invisibly in his films, editing the seams out of the frame until we cannot tell which images make up 'the image' we can see, yet explicitly tells us he is doing so when discussing his work. In the viewing notes for his film Sleep Has Her House (2017), he writes that the film is 'akin to paintings that move, mixing live action, still photography, and hand-drawn images' (Barley 2017b). This heavily recalls Joret when he explores Bazin's views on cinema and painting. The media blur particularly in the case of impressionist works by van Gogh. While watching the film, we cannot see where a photo begins, or where a phone-captured live-action shot ends. Instead, an overt, yet ambiguous, timespace is created in the visual database of the film. His work emerges from an existing database (and thus is a database film), as a database in itself, which contains 
several other databases within it. Each image we see is a collection of multiple shots displayed simultaneously. We cannot tell where each image comes from, or when - one part could be several years old, while another could be hours; one part could be a shot of the natural world, the other a drawing. It leads us to what Jean-Luc Nancy and Aurelien Barrau would describe as 'the consideration of a struction: the uncoordinated simultaneity of things or beings.' (2015, 49). Manovich's 'pure database' is therefore one which does not place a communicable order or hierarchy on objects or information. It is a database we know exists yet, so far, cannot comprehend. The idea of a structure to the database is abandoned, and instead the affective database emphasises the limits of our perception through explicitly figuring that which we cannot figure - struction. This is not limited to a particular aesthetic experience. Sleep Has Her House is a slow, melancholic film featuring shots that are several minutes long. In its slow time it 'brings about a renewed awareness of temporality and the opportunity to imagine different worlds' (de Luca 2016, 42), whereas his film Blue Permanence / Swan Blood (2015a) is a sixminute short that crackles and bursts with hyperactive movement such that whatever images once constituted the database from which it emerged can no longer be said to exist independently, but instead bleed into each other, to the extent that we can no longer recognise anything remotely connected to our own perception.

Tiago de Luca said of slow time that it solicits a 'mode of spectatorship that reflects on its own phenomenology as a collective act of physical coexistence and lived experience in time' (2016, 42), an idea that Barley engages with directly. He tells us:

my aim is to make you - the viewer - become the protagonist of the film, to be the avatar itself, wherein you are emblazoning yourself upon the images, through and into them, exploring its worlds, through darkness and light, along with me. (Barley, Notes On Cinema)

Despite clear instructions to anonymise the viewing space in which we watch his films (Barley instructs that they must be watched in complete darkness, at a low screen brightness, with headphones or surround sound), this is not an attempt to isolate the viewer, but rather to open them to an entanglement with the film and filmmaker. This is heightened further by the ambiguity of Passing (2013c) and Closer (2016a), visually arresting films that obscure their purpose. William Brown writes of entanglement that it arises when 'participation is required in the ethical process of choosing what to believe' $(2018,218)$. Barley's work would fit neatly into Brown's definition of non-cinema, where we realise that 'the film works on the spectator as the spectator is actively involved with the film' $(2018,48)$. Thus, we are entangled with the film, and it with us.

Barley can be said to entangle himself too. Brown also writes that 'to pick up a camera and to record is, in Barad's language, 'to acknowledge [...] that one is becoming as the world is becoming, and that one is, therefore, involved in the creation of new worlds' (2018, 63-4). The creation of his own database of images leads Barley to become as his world becomes, and in the emergence of films from this database he is also involved in the creation of new worlds. These arise from the unique timespaces (or dreamspaces) his films create. They are film worlds in which 'what is constantly rekindled and renewed is the very possibility of the world - or rather the multiplicity of worlds.' (Nancy and Barrau 2015, 52). Each holds the possibility of 
showing us, the viewers, new and exciting ways to perceive and see, to experience something beyond our usual perception. Each of Barley's films 'invoke worldhood in different ways. Their "ultimate referent" is not a thing or a place but a mode of involvement' (Pick and Narraway 2013, 32). Entanglement and the diegesis of the spectator become this mode of involvement, such that we are viewer-participants. The database itself becomes an involvement with the world. But to what do we refer when we refer to the world? And, following this, what then does 'worldhood' mean?

\section{Worldhood, Unknowable}

If each film creates its own film-world then they are each different to our own 'world'. Barley's films, especially those such as Evenfall (2015b), and Hinterlands (2016b), present worlds that are not only different to our own, but specifically embody animal or mineral perceptions. The unpredictable temporalities (featuring jumps, slips and pauses) and impossible visuals created from the layering of images recall worlds that feel alien rather than terrestrial. The act of perceiving becomes an unfamiliar one, and we lose the footholds of that which grounds us in our world - our senses. Though we can occasionally see an image of something we recognise in Hinterlands, the treachery of Barley's images creates a processual doubt in our thinking and before we know it, what we thought we had recognised is replaced by something altogether different. Anat Pick and Guinevere Narraway remind us that while 'animals' worlds are irreconcilably different, the fact that they all inhabit $a$ world is not. This alone is a powerful appeal for a more-than-human conception of worldhood' $(2013,30)$. Our reconciliation of these unfamiliar territories comes from the realisation that, although we can never be 'part' of these worlds, we know that each being, each thing, is part of $a$ world. The boundaries can be looked across, especially when we see that, as Barley himself writes, 'to truly submit to the cinema experience is like letting the waves of the ocean crash over you and not be afraid of drowning [...] to give oneself up to the other' (Notes On Cinema).

It is useful here to loosely define film worlds (since they are multitudinous, 'irreconcilably different' timespaces), and Daniel Yacavone's explanation feels most prudent. He writes that, firstly, film worlds can emerge as perceptual and symbolic objects to be analysed and that:

secondly, they may be seen 'from the inside' as durational and affective experiences that are fundamentally irreducible, with a focus on the immersive (and intuited) nature of their expression. $(2008,86)$

It is primarily the second part of his definition that I engage with. Yacavone eventually posits that these latter film-worlds require a subject through which the creator of the aesthetic object is identified. His theorisation of these worlds is primarily concerned with 'director-specific feeling or affect' $(2008,100)$. My conception of film worlds departs from Yacavone's here. He takes this duality further, calling film worlds 'object-experiences which may be described in terms of the polarities of external/internal, objective/subjective, representational/expressive, ontological/phenomenological' $(2008,105)$. In this way Yacavone's film worlds ignore the potentials of an entangled view of cinema as an affective medium viewers participate in and become-with by separating it through binary structures. The non-dual film world allows a 
marriage of geographical and temporal peripheries to form them, breaking away from the limitations of an auteur approach in which films are dead on arrival, rather than being enchanted with an afterlife post-creation that allows them to ecstatically change us and be changed by us in their interactions between the borders and peripheries of their worlds. Lucia Nagib promotes this entanglement too, writing that in multicultural societies, films simply cannot be seen as 'the other', and that 'more interesting than their difference is, in most cases, their interconnectedness.' $(2011,1)$. The focus on interconnectedness is ethically essential, both for highlighting similarities between peripheral film worlds and temporalities, but also for the way it necessarily defines difference through this interconnection. Both are key to understanding and appreciating the vast constellations and galaxies of worlds that continually form and reform our existence.

However, this conception of film worlds must evolve further. Peripheries of cinema are not just limited to the geographical or the temporal, but to the formal too. Marginal and evolving conceptions of cinema itself are also key to this theory of many worlds. Rather than the cold, calculated analysis of features and symbolic interpretation we instead affectively encounter these worlds, allowing their waves to crash over us as we become-with their formation. Despite not being part of these worlds, our immersion in them becomes a route to limited experience, though experience nonetheless. Barley attests to this experience: 'In these moments of the camera becoming the body, we, the spectator assume the body of the protagonist' (Notes On Cinema). They are immersive precisely because of their irreconcilability with our perceptual experience. They are dark worlds, literally in their underexposed presentation, and figuratively in the unknowable nature of their worldhood - their existence in the world, and their figuration of a world.

\section{Darkness and Simulation}

The creation of database cinema, especially in its recycled/re-used form, can inevitably be criticised as the creation of a facsimile, an imitation. In Franco 'Bifo' Berardi's words, it would be a simulation, 'a copy which has no prototype, the imitation of something that does not exist, and has never existed except in the simulator's mind' $(2015,99)$. Berardi talks about this simulation as a facet of 'semiocapitalism', his name for the regime of endless information flows valourising capital that embody nothing but simulations, recalling and evolving heavily from Baudrillard's Simulacra and Simulation (1994). For Nancy and Barrau (as for Baudrillard), these simulations mean nothing - behind their shallow facades lies the truth of 'sign and sign and nothing' $(2015,9)$. Simulation is borne into the world from the darkness of the mind, and embodies the true darkness of 'nothing', no meaning. For Berardi, to simulate is a conscious choice of translation from mind to world, and so this darkness from which it emerges is not really a darkness. Instead, it is known by the creator (in this case the creator of the database), and emerges from the light of an idea, a conscious, pernicious thought of simulation that merely follows the previous iteration. With Barley, however, as well as obscuring his database in the invisible editing of images, he similarly obscures from himself the very idea of making a film. He explains that in the process of creation 'I have no idea, or agenda to make a film. I simply document. I shoot what attracts me ... once I have built up a body of footage, I start to see 
connections' (Notes On Cinema). Barley's lack of objective (mission) while filming means that his films emerge from the darkness of preconsciousness; the unthought, or perhaps through intuition. In place of the conscious elaboration of the rhythms of semiocapitalism, the films instead are formed with no sign from which to begin down that path. Maurice Merleau-Ponty's immanent significance emerges as the first referent, allowing appeals to memory that do not rely on the previous iterations of signs, and thus Barley creates viewing-experiences along with us, who ourselves sees his films emerge as immanently (sign)ificant. Barley's work is unwatchable in the light of semiocapitalism, just as it is unwatchable in light. His underexposed images can only be seen on a dimmed screen in a dark room - a non-space, created because 'I feel like I don't belong in either place fully; not the internet, not the cinema' (Barley, Notes On Cinema). To block out the light is to see clearly these non-human film worlds; we must create the non-space to view the new space.

Given our participation in Barley's films as protagonists in an unknowable world, the boundaries between the films and us bleed into one another. The absence of figures and presence of figurations encourages this; the disembodied hand reaching from the screen into the background in The Sadness of the Trees (2015d) becomes embodied by the viewer. By the time Womb (2017c) is released, the hand instead reaches out towards us, acknowledging our presence in the film world. These abstracted figurations and lack of clear narratives allow our minds to wander and become hypnotised by images whose meaning we are invited to create, abandoning semiocapitalism's conscious rhythm of thought. Berardi invokes Felix Guattari's term chaosmosis to describe this - 'the shift from a rhythm of conscious elaboration (refrain) to a new rhythm, which is able to process what the previous rhythm could not process' (2015, 115). The new rhythm we find ourselves in rejects the constant exhaustion and depression that form key bodily affects of semiocapitalism (Parikka 2015), replacing endless information flows with periods of nothing, of slowness, and the lack of thought that emerges as the unthought. The release of Barley's film The Green Ray (2017a) attests to this. The film is composed of a single shot - though how singular an affective database is we do not know - taken from the multitude of images that form Sleep Has Her House. It is eleven minutes in length and displays the setting of a sun and the emergence of a lightning storm over water. To describe the image does seem to kill it, and so we must think about what this image can do, in that it can allow us a period of 'nothing', in which we immerse ourselves. The film feels significant, and meaningful, yet does not come from any recognisable form of perception that we know. Its temporality is distinct from our own, its signs do not exist. Although we see the lightning and the water, the film world feels so utterly alien to our own, so distinct from how we engage in our own acts of worldhood, that our referent to it exists only as fleeting recognition that regresses instantaneously into the darkness of the screen. The act of viewing this single, long shot creates meaning from nothing. Not the nothing that hides in plain sight in semiocapitalist simulacra, but the nothing immanent to the creation of Barley's film worlds, an unthought nothing. If Berardi's simulation (from the Latin similis, meaning 'like, resembling') is the refrain of 'sign and sign and nothing' (Nancy and Barrau 2015,9) we are in a rhythm of 'nothing and nothing and meaning', or symulation (from symbiote) in which there is togetherness, a sharing, a becoming-with, a being-with the world(s). Darkness inherently 
engenders symulation, which becomes a collective act of meaning creation between film, filmmaker, and viewer-participant. The darkness referred to here, and to which Barley's work is also referent is one that precedes light. This darkness is one that cinematic light cannot ever reach in the same way the expansion of the universe prevents the light from distant stars reaching us. This is not to say that we are the centre to which this darkness is related, but that darkness is instead the centre from which light may emerge. The darkness of The Green Ray is twofold. It is the darkness of the images themselves, and of the multitude of images that will be added to it that we cannot see; the myriad other projects that its composited images might be recycled in by Barley.

\section{Socialist Symulation}

We cannot, however, get distracted by the wonders of the affective database without critiquing the privilege it takes to create and encounter one. Jussi Parikka (2015) reminds us that smartphones contain dozens of rare metals, reminding us of the scourging of resources enacted by late capitalism. These are rendered unseen by the design of the phone, hiding its internal components. Even the metallic nanoparticles, aerosolised in the brushing and polishing of the phone's metal casing, obscures this. The slow violence (Nixon 2013) wrought over the past five centuries connects all our modern technology to the destruction of the natural world. There is no escape from this. There are, instead, only steps one can take to mitigate it.

The production of Barley's films minimises this worldly impact technology can have. There are no additional purchases of expensive digital equipment, no reshoots or rentals. There is no crew to transport nor natural spaces to ravage with boots and lights and generators. These are ecocinematic practices. Traditionally, ecocinema would be heralded as slow, a form of cinema that reduces kinetic movement of cameras and increases attention spans, which seems to fly in the face of Barley's more hyperactive, ecstatic works. John Landreville counters, suggesting 'a formalist theory of ecocinema that is more affectively, rather than reflectively, attuned and more immanent in its focus' $(2019,106)$. Barley's use of his smartphone does not, generally, extend past normal use when considering the day-to-day proliferation of images around the world. The filmmaker submits himself to encounters in the world, rather than seeking out or uncovering a desired encounter, which not by chance recalls the seeking out and uncovering of minerals from the topsoil and below in endless capitalist production. Throughout the process, Barley submits to creation without conscious intention. He describes his films as emerging from the struction of footage he has stored, themselves evoking simultaneity for us as viewerparticipants. Thus, we collectively create the meaning in Barley's films, and collectively engage in the ecocinematic process he catalyses. Brown writes that:

making a film in part with a smartphone suggests a deference towards rather than a desire to dominate reality. This democratization of cinema...is in some senses a socialist manoeuvre. $(2018,224)$

I suggest that this provokes us to think of symulation in the same way. Rather than a method of exercising control, symulation is a submission of control, a loss of control together, that affectively gives us over to the creation of meaning that is immanent to the viewing experience, 
and not exercised consciously by us. Thus, the new unconscious rhythm, the unthought, allows us to socialise through the experience, and defer to immanence - a socialist manoeuvre.

\section{Losing Control of Cinema}

The loss of control inherent to symulation is reflected in Barley's films, where language becomes insufficient, and indeed unable, to communicate effectively. This is not just spoken or written language, but language as an idea. Brown suggests that non-cinema is, in a sense, beyond language, and that 'language, it would seem, or the process of reification and the assignation of use value, is in the services of cinema-capital.' (2018, 247). I would take this further and argue that the affective database is not just beyond language, but beyond referent. Thus, it is beyond cinema and non-cinema also. Where cinema and non-cinema held shots that tell stories and images that communicate information there is, in the affective database, 'nothing but a deluge of pure, unadulterated feeling; feeling alone. And pure feeling cannot and should not be translated into rational thought' (Barley, Notes On Cinema). We feel this embodied (un)clearly in Polytechnique (2014), an attempt of Barley's to create 'prisoner's cinema', the appearance of ill-defined and indescribable light and colour that occurs in the vision of those who spend a lot of time in darkness. As we have seen, all of Barley's work emerges from darkness, and it is in darkness that we find ourselves becoming-with the film worlds. It is there, too, that Barley's films begin to take hold of us as nothing but 'feeling alone'. The collaboration with musician Easychord in Polytchnique complements this further. His droning score features what we could figure as memories of orchestral and operatic music that never become fully realised. They are always subsumed by the darkness. Instead, we feel the presence of this musical memory through its near absence, submitting ourselves to the feeling it gives us, to the strain it engenders in our ears, and the recognition of an immanent significance that we find emerging from the nothing. Barley's films all defy language and the use of it. Some even play with this defiance, opening or closing with poetry that never displays on an image, only a black screen. The 'language' of cinema is rendered void through his work, and instead of a stratified and hierarchical logic underpinning decisions to cut, dissolve, layer and darken there is the beat of the unthought, unconscious rhythm of symulation that submits control. The layering of images especially provokes this. Where cinema's language would have been there are instead indistinct cuts and dissolves and layers one on top of the other in nonsensical fashion. Language becomes incomprehensible like this. For example, were the same to be done with this study, words layered one upon the other, it would appear as only this: in the middle of a black page - unknowable, though even if it were it would not be sens(e)ible - it is only through cinema that this can happen.

For this is a cinema of losing control, through the submission of the idea that we could ever have had some over these strange worlds. Just as Barley submits himself to a stream-ofconsciousness filmmaking process, so too do we submit the viewing of these films to the unconscious rhythm, in another parallel that forms the viewer-participant dynamic we inhabit with the filmmaker. We are de-centered by this, opening ourselves to animal and mineral perceptions through a foregrounding of a sensual experience that lies in the background of capitalism - the experience of the Other. 


\section{Noisy Constellations}

The foregrounding of Othered perceptions becomes a positive gain for us as human beings. Though I do not argue that one could become a minority, given the political connotations of the idea, we do decenter our experience as anthropocentric humans, in favour of nonanthropocentric thoughts and perceptions. Thus, what we gain is an appreciation of the effects of chaosmosis, where we encounter these non-human rhythms. In Barley's work, and perhaps all affective databases, the unthought/non-thought becomes the central component of lived experience. Following Nancy and Barrau:

it is not a matter of thinking differently, but of thinking in a place where thought does not have any currency [...] of unistruction: the struction of the ones, a contingent and proliferating struction $[\ldots]$ that does not subsume singularities. $(2015,88)$

We feel this unistruction in the database, in the layered and composited images that we affectively encounter in his films. The images are still constructed of singularities but unify on the screen and in our eyes into a (dis)organised wave of perception. We see it more concretely in the form of digital noise, especially Nightwalk (2013) and Passing. Both films are visual negatives, portraying darkness as light and light as darkness, although the digital editing technique leaves significant imprints on the image. Instead of true darkness and true light there is a multitudinous swarm of luminous dots and (in his colour films) colours that stem from digital technology trying to artificially 'make light' the darkness.

The particles of noise recall Parikka's assertion that 'nanoparticles are everywhere and form societies unseen and unheard of, yet they conglomerate on a scale unimaginable to human beings. We are a minority' $(2015,86)$, and so this noise reminds us that we too are a minority compared to the vast number of unknowable worlds that exist beyond-perception and therefore beyond thought. Barley's preoccupation with star-fields create this feeling too. The firmaments of Womb and Hunter (2015) envelop us, surrounding our viewing-space (non-space) with a multitude of stars that we know are far beyond our scale of comprehension. Stars are an essential affect of cinema for Barley, who thinks that 'perhaps we have no purpose except to one day return, to pass through that mirror, and reunify with the stars that birthed us' (Notes On Cinema). Constellations, thus, are a key part of the invitation to non-human perception that his films hold, and these constellations are themselves multitudinous. There is the constellation of images layered one on top of the other, and the constellation of filmmakers that Barley aligns himself with. There is the constellation of film worlds that hold yet more constellations of perception and there are of course several images of constellations and through this there is an ever-reflective infinity of noise that tries to make the darkness seen: non-human perception perceived.

\section{Infinite Deaths}

Barley's cinema alters our thoughts and elicits images and rhythms of non-human perception, seeing from many angles at once, or seeing deep time from outside of that timespace. The noisy constellations constantly pull us back to the stars in infinite repeated deaths, or rather, entropic disorganisations as our atoms return time and again to the star-fields they came from. It is no 
wonder that bodies are complicated ideas in his work. Often they are ghosts - imprints and affective recollections of bodies (Nightwalk, and Irresolute (2013a) especially) are common, but in Womb bodies are shown within the star-fields as vast, cosmic horrors recalling Lovecraft (though these bodies are waiting for consciousness before they can wreak their havoc once more). One gets the feeling when watching that they have returned time and again, and now lie in death waiting for a re-birth. These ghostly apparitions are, phenomenologically speaking, an affect of interaction between worlds and us: a non-local, temporally unstable expression of perception, time and place. Their abstracted nature and inhabitation of non-human worlds evokes the idea that 'the world is itself the "subject" of which we are an affect' (Nancy and Barrau 2015, 4-5). To become a ghost is to have died, which we do as we lose our anthropocentrism. Barley's work (and, I would suggest in some cases, cinema in general) is uniquely positioned to communicate these deaths. Thomas Wartenberg claims that 'because of their ability to depict motion, [films] also have the possibility of depicting stasis, something that is surprisingly not possible in a static medium' $(2011,21)$. Stillness, as distinct from slowness, is a lack of rhythm and is inherently connected to death, and so I would not argue that Barley's films are depictions of stillness itself. However, the slowness and non-human rhythm of his cinema suggests a 'slow aesthetics' (not necessarily slow cinema), that is created slowly, displays slowly, and slows our thoughts. This is particularly true of Painting (I) (2016c) which visualises on screen a thirty-second phone-captured shot of tree branches in wind as a six-hour series of frames, each one completely still. Movement is slowed to such an extent that periods of stillness can appear. Barley's work contains many such instances, where we are slowed to a rhythm that allows the perception of stasis that semiocapitalism otherwise refuses us. Thus, we perceive the ultimate non-human experience of death, and find ourselves truly in other worlds.

\section{References}

Barley, S. (no date) Notes On Cinema. Available at: https://scottbarley.com/Notes (Accessed: 20 September 2021).

Baudrillard, J. (1994) Simulacra and Simulation. Ann Arbor, MI: University of Michigan Press.

Berardi, F. (2015) Heroes, Mass Murder and Suicide. London: Verso.

Blue Permanence / Swan Blood (2015a) Directed by S. Barley. United Kingdom: Ether Films.

Brown, W. (2018) Non-Cinema: Global Digital Film-making and the Multitude. London: Bloomsbury.

Closer (2016a). Directed by S. Barley. United Kingdom: Ether Films.

de Luca, T. (2016) 'Slow Time, Visible Cinema: Duration, Experience, and Spectatorship', Cinema Journal, 56(1), pp. 23-42.

Evenfall (2015b) Directed by S. Barley. United Kingdom: Ether Films. 
The Green Ray (2017a) Directed by S. Barley. United Kingdom: Ether Films.

Hinterlands (2016b) Directed by S. Barley. United Kingdom: Ether Films.

Hunter (2015c) Directed by S. Barley. United Kingdom: Ether Films.

Irresolute (2013a) Directed by S. Barley. United Kingdom: Ether Films.

Kinder, M. (2003) 'Designing a Database Cinema', in Shaw, J. and Weibel, P. (eds.) The Cinematic Imaginary after Film. Cambridge MA: MIT Press, pp. 346-353.

Landreville, J. (2019) 'Alternative ethics for ecocinema: The Tree of Life and post-continuity aesthetics', New Review of Film and Television Studies, 17(1), pp. 99-119.

MacDonald, S. (2004) 'Toward an Eco-Cinema', Interdisciplinary Studies in Literature and Environment, 11(2), pp. 107-132.

Man with a Movie Camera (1929) Directed by D. Vertov. Soviet Union: VUFKU.

Manovich, L. (1999) 'Database as a Symbolic Form', Convergence, 5(2), pp. 80-99.

Merleau-Ponty, M. (2002) Phenomenology of Perception. London: Routledge.

Nagib, L. (2011) World Cinema and the Ethics of Realism. London: Continuum.

Nancy, J. L., and Barrau, A. (2015) What's These Worlds Coming To? Translated from the French by T. Holloway and F. Méchain. New York: Fordham University Press.

Nightwalk (2013b) Directed by S. Barley. United Kingdom: Ether Films.

Nixon, R. (2013) Slow Violence and the Environmentalism of the Poor. Cambridge, MA/London: Harvard University Press.

Painting (I) (2016c) Directed by S. Barley. United Kingdom: Ether Films.

Parikka, J. (2015) A Geology of Media. London/Minneapolis, MN: Minnesota Press.

Passing (2013c) Directed by S. Barley. United Kingdom: Ether Films.

Pick, A., and Narraway, G. (eds.) (2013) Screening Nature: Cinema Beyond the Human. New York, NY: Berghahn Books.

Polytechnique (2014) Directed by S. Barley. United Kingdom: Ether Films.

The Sadness of the Trees (2015d) Directed by S. Barley. United Kingdom: Ether Films.

Sleep Has Her House (2017b) Directed by S. Barley. United Kingdom: Ether Films.

Vesna, V. (2007) Database Aesthetics: Art in the Age of Information Overflow. Minneapolis: University of Minnesota Press.

Wartenburg, T. (2011) 'On the Possibility of Cinematic Philosophy', in Carel, H. and Tuck, G. (eds.) New Takes in Film Philosophy. London/New York: Palgrave Macmillan, pp. 9-24.

Willoquet-Maricondi, P. (ed.) (2010) Framing the World: Explorations in Ecocriticism and Film. Charlottesville: University of Virginia Press. 
Womb (2017c) Directed by S. Barley. United Kingdom: Ether Films.

Yacavone, D. (2008) 'Towards a Theory of Film Worlds', Film-Philosophy, 12(2), pp. 83108.

Jack Buchanan is a graduate of the MRes Humanities at the University of Stirling, following a Film and Media degree and (in another life) short tenure as a student nurse there. His research interests include rhythm, worldhood, and new and emerging forms of cinema, with a particular focus on apocalyptic imagery, space, and entropy. While working through the pandemic in the NHS he continues to hum and ha about $\mathrm{PhD}$ research, and in the meantime welcomes the opportunity to talk, think and collaborate with others on a wide range of academic and creative projects.

Email: jackb29@live.co.uk 